\title{
Bioanalysis
}

\section{D-LC-MS/MS to measure cleaved high- molecular-weight kininogen in human plasma as a biomarker for C1-INH-HAE}

\begin{abstract}
Aim: C1-INH-HAE is caused by activation of plasma kallikrein which subsequently cleaves high-molecular-weight kininogen (HMWK) to generate bradykinin and CHMWK. Materials \& methods: A novel ion-pair 2D LC-MS/MS assay was developed to measure the $46 \mathrm{kDa}$ CHMWK in plasma as a biomarker for C1-INH-HAE. The sample preparation included sodium dodecyl sulfate denaturation, methanol crash, chymotryptic digestion and peptide enrichment by solid phase extraction. Results: The LLOQ was $200 \mathrm{ng} / \mathrm{ml}$. The overall cHMWK recovery combining crash and digestion was $57.5 \%$. The precision of the method was $\leq 12.7 \%$ and accuracy $\leq-13.8 \%$. Conclusion: $A$ reagent-free LC-MS assay has been developed for the quantitation of $46 \mathrm{kDa}$ cHMWK, which was shown to be elevated in plasma of C1-INH-HAE patients due to C1-INH deficiency relative to that of healthy subjects.
\end{abstract}

First draft submitted: 10 May 2017; Accepted for publication: 3 August 2017;

Published online: 21 October 2017

Keywords: C1-INH-HAE biomarker • cleaved high-molecular-weight kininogen • ion-pair 2DLC-MS/MS • protein biomarker

Hereditary angioedema (HAE) due to a genetic deficiency in total or functional C1-INH (type I and type II C1-INH-HAE, respectively) leads to dysfunctional regulation of contact system activation and excess bradykinin generation. Type I C1-INHHAE constitutes approximately $85 \%$ of these patients with the remainder being type II [1]. C1-INH is a serpin that inhibits a number of proteases including the $\mathrm{C} 1 \mathrm{com}$ plex in the classical complement pathway as well as contact system proteases, coagulation factor XIIa and plasma kallikrein [2,3]. While C1-INH-HAE type I or type II is attributed to mutations in one of the two C1-INH alleles, other forms of angioedema exist including HAE with normal C1-INH, recurrent idiopathic angioedema and acquired angioedema [4-6]. Clinical symptoms of C1-INH-HAE include episodic swelling of subcutaneous tissues, bowel walls, upper airways and the recurrent cuta- neous edema affecting the face, extremities, trunk and genitals [7].

High-molecular-weight kininogen (HMWK) is a single-chain glycoprotein with a molecular weight of approximately $120 \mathrm{kDa}$ and present in systemic circulation at a concentration of about $80 \mu \mathrm{g} / \mathrm{ml}$ and plays a central role in the activation of contact system [8]. Recurrent activation of the contact system generates excess plasma kallikrein, a proteolytic enzyme that primarily cleaves HMWK between Lys $_{380}-\operatorname{Arg}_{381}$ and $\operatorname{Arg}_{389}-\mathrm{Ser}_{390}$ residues to release the nine amino acid peptide bradykinin. The resulting cleaved kininogen (cHMWK) contains two chains linked together by an interchain disulfide bond, the heavy chain (66 kDa) containing domains 1-3 and the light chain $(56 \mathrm{kDa})$ containing domains 5-6. The $56 \mathrm{kDa}$ light chain in cHMWK (denoted $56 \mathrm{kDa}$ cHMWK) can be further cleaved by plasma kallikrein at the $\mathrm{N}$-terminal por-
Guodong Zhang*,1, Daniel J Sexton², Ryan R Faucette ${ }^{3,1}$, Yongchang Qiu' \& Jiang $\mathrm{Wu} * *, 1$

'Bioanalytical \& Biomarker Development, Research \& Nonclinical Development, Shire, Lexington, MA 02421, USA 2Pharmacology, Research \& Nonclinical Development, Shire, Lexington, MA 02421, USA

${ }^{3}$ Scholar Rock, Cambridge, MA 02139, USA

*Author for correspondence:

Tel.: +1 7814821993

gzhang@shire.com

**Author for correspondence:

Tel.: +1 7814821493

jwu@shire.com

newlands press part of 
tion of the polypeptide to generate a $46 \mathrm{kDa}$ light chain (denoted $46 \mathrm{kDa}$ cHMWK) as the final cleavage product (Figure 1) [9-12]. The bradykinin released from HMWK acts as a key mediator of pain, inflammation, edema and angiogenesis [13]. Dysregulated plasma kallikrein proteolysis of HMWK can result in accumulation of bradykinin, which induces vasopermeability resulting in the edematous attacks associated with C1-INH-HAE [12,14-17]. Therapeutic intervention by inhibition of plasma kallikrein has led to acute and prophylactic treatments of C1-INH-HAE [18-21].

Biomarkers of contact system activation, such as plasma cHMWK and bradykinin, can provide insight into the pathobiology of bradykinin-mediated angioedema and potentially improve diagnosis and patient management. Such biomarkers could also facilitate the evaluation of treatment efficacy [21]. Previous reports using plasma biomarkers of contact system activation, including cHMWK, have shown that plasma kallikrein is generated during C1-INH-HAE attacks [6,9,2224]. As a result, there is considerable interest in developing sensitive and reliable assays to measure the level of cHMWK as a potential biomarker for C1-INHHAE [10,24-25]. Due to the lack of appropriate immunoassay reagents to specifically detect cleaved products, western blotting has currently been utilized to measure the cHMWK concentration for a variety of angioedema conditions and correlate it with drug efficacy in the early stage of clinical study [12,18-20,24]. It represents a challenge to validate the western assays since they are generally semiquantitative, variable and of low sample throughput. As such, an immunoassay for cHMWK based on the discovery of a proprietary antibody capable of selectively measuring cHMWK in the presence of high abundance of its precursor HMWK protein has recently been developed (manuscript in preparation).

LC-MS/MS has become an attractive technique to measure protein biomarkers in biological samples due to its superior selectivity and specificity [26-33]. The LCMS/MS approach quantifies a protein by selectively analyzing an appropriate surrogate peptide (SP) derived from the target analyte using multiple reaction monitoring (MRM). A great deal of progress has been made to enhance the specificity and sensitivity for the detection of low abundance proteins by reducing sample complexity through immunoprecipitation (IP) or multidimensional chromatographic fractionation at protein and/or peptide levels prior to LC-MS/MS [34-36]. Recently, we described an online 2D-LC-MS/MS platform for therapeutic protein quantitation in the presence of antidrug antibodies [37]. The orthogonal separation of peptides by the 2D-LC substantially enhances sensitivity of the assay, allowing for low-nanogram quantitation of protein therapeutics in clinical samples. We present here a novel ion-pair 2D-LC-MS/MS assay combined with specific pellet digestion using chymotrypsin to measure $46 \mathrm{kDa}$ cHMWK in human plasma. The assay was reliable, robust and was validated following the regulatory guideline [38]. We demonstrate that the $46 \mathrm{kDa}$ cHMWK isoform is able to differentiate C1-INH-HAE patients and healthy individuals and could potentially be used as a disease biomarker after further investigation.

\section{Materials \& methods \\ Materials}

The human cHMWK and HMWK (Uniprot version 186, accession number P01042; molecular weight $\sim 120 \mathrm{kDa} ; 95 \%$ pure) were purchased from Enzyme Research Laboratories (IN, USA). The proteins were supplied as a stock solution of $1.40 \mathrm{mg} / \mathrm{ml}$ (cHMWK) and $1.91 \mathrm{mg} / \mathrm{ml}$ (HMWK), respectively. SDS-PAGE gel of the reduced cHMWK confirmed that the $46 \mathrm{kDa}$ fragment was the predominant light chain, whereas $56 \mathrm{kDa}$ cHMWK isoform was minimally present in the commercial preparation. Tosyl-L-lysine chlorometyl ketone (TLCK)-treated chymotrypsin was from Sigma-Aldrich (MO, USA). Lys-C was purchased from Wako (Osaka, Japan). Mass spec grade proteinases Asp-N and Glu-C were obtained from Promega (WI, USA). Dithiothreitol (DTT), iodoacetamide (IAA), ammonium bicarbonate (ABC), ammonium hydroxide, urea, formic acid (FA), trifluoroacetic acid (TFA), heptafluorobutyric acid (HFBA), HPLC grade methanol $\left(\mathrm{CH}_{3} \mathrm{OH}\right)$ and acetonitrile $\left(\mathrm{CH}_{3} \mathrm{CN}\right)$, sodium dodecyl sulfate (SDS) solution (10\%) and phosphatebuffered saline (PBS) were all purchased from SigmaAldrich (MO, USA). The MCX 96-well plate $(30 \mu \mathrm{m}$, $10 \mathrm{mg}$ ) was obtained from Waters (MA, USA). The unlabeled SP, KHNLGHGH and ${ }^{13} \mathrm{C}$-labeled internal standard (IS), KHNL $\left[{ }^{13} \mathrm{C}_{6}\right] \mathrm{GHGH}$, were custom-synthesized at New England Peptide (MA, USA) (>95\% purity). A $10 \times$ protease inhibitor cocktail (SCAT169) solution was prepared in house and contains $100 \mathrm{mM}$ benzamidine, $400 \mu \mathrm{g} / \mathrm{ml}$ polybrene, $2 \mathrm{mg} / \mathrm{ml}$ soybean trypsin inhibitor, $20 \mathrm{mM}$ EDTA, $263 \mu \mathrm{M}$ leupeptin, $20 \mathrm{mM}$ AEBSF, $100 \mathrm{mM}$ trisodium citrate and 2\% dextrose. Evacuated, plastic blood collection tubes (SCAT169-4.5/5) containing the above 10x protease inhibitor cocktail were provided by Haematologic Technologies Inc. (VT, USA). Control human plasma collected in SCAT169 tubes was obtained from Bioreclamation Inc. (NY, USA).

\section{SP selection}

To probe the appropriate SP to distinguish cHMWK and HMWK, the two proteins were denatured in $8 \mathrm{M}$ urea, reduced with $5 \mathrm{mM} \mathrm{DTT}$ at $37^{\circ} \mathrm{C}$ for $60 \mathrm{~min}$, alkylated with $5 \mathrm{mM}$ IAA for $30 \mathrm{~min}$ at ambient tem- 


\begin{tabular}{llllll} 
MKLITILFLC & SRLLLSLTQE & SQSEEIDCND & KDLFKAVDAA & LKKYNSQNQS & 50 \\
\hline NNQFVLYRIT & EATKTVGSDT & FYSFKYEIKE & GDCPVQSGKT & WQDCEYKDAA & 100 \\
KAATGECTA & VGKRSSTKFS & VATQTCQITP & AEGPVVTAQY & DCLGCVHPIS & 150 \\
TQSPDLEPIL & RHGIQYFNN & TQHSSLFMLN & EVKRAQRQVV & AGLNFRITYS & 200 \\
IVQTNCSKEN & FLFLTPDCKS & LWNGDTGECT & DNAYIDIQLR & IASFSQNCDI & 250 \\
YPGKDFVQPP & TKICVGCPRD & IPTNSPELEE & TLTHTITKLN & AENNATFYFK & 300 \\
IDNVKKARVQ & VVAGKKYFID & FVARETTCSK & ESNEELTESC & ETKKLGQSLD & 350 \\
CNAEVYVVPW & EKKIYPTVNC & QPLGMISLMK & RPPGFSPFRS & SRIGEIKEET & 400 \\
& & & & 438 & \\
TVSPPHTSMA & PAQDEERDSG & KEQGHTRRHD & WGHEKQRKHN & LGHGHKHERD & 450 \\
QGHGHQRGHG & LGHGHEQQHG & LGHGHKFKLD & DDLEHQGGHV & LDHGHKHKHG & 500 \\
HGHGKHKNKG & KKNGKHNGWK & TEHLASSSED & STTPSAQTQE & KTEGPTPIPS & 550 \\
LAKPGVTVTF & SDFQDSDLIA & TMMPPISPAP & I QSDDDWIPD & IQIDPNGLSF & 600 \\
NPISDFPDTT & SPKCPGRPWK & SVSEINPTTQ & MKESYYFDLT & DGLS &
\end{tabular}

Figure 1. Amino acid sequence of high-molecular-weight kininogen ( $\mathrm{Gln}_{19}-\mathrm{Ser}_{644}$; Uniprot v186, accession number P01042). Proteolytic cleavage by circulating kallikrein releases bradykinin $\left(\mathrm{Arg}_{381^{-}}-\mathrm{Arg}_{389^{\prime}}\right.$ green), and the CHMWK that is composed of a heavy chain $\left(\mathrm{Gln}_{19}-\mathrm{Lys}_{380^{\prime}}\right.$, blue) and a $56 \mathrm{kDa}$ light chain ( Ser $_{390}-\mathrm{Ser}_{644}$, red) linked by an interchain disulfide bond $\left(\mathrm{Cys}_{28}\right.$ and $\left.\mathrm{Cys}_{614}\right)$. Further cleavage of the $56 \mathrm{kDa}$ light chain by kallikrein gives rise to a $46 \mathrm{kDa}$ light chain ( Lys $_{438}-\mathrm{Ser}_{644}$ ) and exposure of a unique C-terminus with the SP generated following chymotrypsin digestion underlined from $\mathrm{Lys}_{438}$ to $\mathrm{His}_{445}$. SP: Surrogate peptide.

perature and subsequently digested overnight at $37^{\circ} \mathrm{C}$ by chymotrypsin (1:50 enzyme/substrate $[E / S])$. The resulting peptide mixture was analyzed on an Orbitrap Velos mass spectrometer (Thermo Scientific, MA, USA). The instrument was operated in the datadependent acquisition mode to collect MS and MS/ MS spectra of the peptides with ion intensities exceeding the predefined threshold (Automated Gain Control target $10^{6}$ ). The mass spectra were searched against the human HMWK sequence database (Uniprot version 186) using Proteome Discoverer software (Thermo Fisher Scientific) to identify peptides and calculate their relative ion intensities.

\section{D-LC-MS/MS conditions}

The 2D-LC-MS/MS system include a Waters UPLC as the first dimension (Waters, MA, USA) connected to an Agilent 1260 Infinity UHPLC (Agilent, Santa Clara, CA, USA) as the second dimension through a six-port, two-position valve built into a QTrap6500 mass spectrometer (Sciex, ON, Canada) with a Turbolonspray source (Sciex) utilizing a positive-ion MRM mode. The first-dimension and second-dimension chromatography utilized the same type of Agilent Metasil AQ C18 Column (Agilent, $2.0 \mathrm{~mm} \times 100 \mathrm{~mm}$, $5 \mu \mathrm{m}$; CA, USA) but different gradient elution conditions (Figure 2). For the first dimension, mobile phase $\mathrm{A}$ $(0.1 \%$ TFA $)$ and mobile phase B $(0.1 \%$ TFA in methanol) were operated at a flow rate of $0.4 \mathrm{ml} / \mathrm{min}$ with the following gradient: $0 \mathrm{~min} / 9.0 \% \mathrm{~B}, 7.95 \mathrm{~min} / 9.0 \% \mathrm{~B}$, $8.0 \mathrm{~min} / 75.0 \% \mathrm{~B}, 12.9 \mathrm{~min} / 75.0 \% \mathrm{~B}, 13.0 \mathrm{~min} / 9.0 \%$
$\mathrm{B}$ and $15.0 \mathrm{~min} / 9.0 \% \mathrm{~B}$. For the second dimension, mobile phase A (0.1\% TFA) and mobile phase B (0.1\% TFA in methanol) were operated at a flow rate of $0.35 \mathrm{ml} / \mathrm{min}$ with a gradient: $0 \mathrm{~min} / 8.0 \% \mathrm{~B}$, $7.6 \mathrm{~min} / 8.0 \% \mathrm{~B}, 13.0 \mathrm{~min} / 45.0 \% \mathrm{~B}, 13.5 \mathrm{~min} / 70.0 \%$ B, $14.8 \mathrm{~min} / 70.0 \% \quad \mathrm{~B}, 14.9 \mathrm{~min} / 8.0 \% \quad \mathrm{~B}$ and $15.0 \mathrm{~min} / 8.0 \% \mathrm{~B}$. Column switch was achieved by the six-port valve, which was placed initially in position 1 during the sample injection and gradient elution of the first LC at which the column eluent was diverted to waste. The LC fraction containing the SP and IS, eluting between 6.0 and $7.3 \mathrm{~min}$ from the first column, was directed to the second column by switching the valve to position 2 at $6.0 \mathrm{~min}$. Shortly after complete elution of the analyte from the first column and transfer to the second column, the valve was switched back to position 1 at $7.3 \mathrm{~min}$, and gradient elution of the trapped peptides from the second column began. All of the original data acquisition and process were performed with Sciex Analyst software, version 1.6.3.

The system was operated in a positive ion MRM mode, and the transition ions were optimized as $\mathrm{m} / \mathrm{z}$ $450.2 \rightarrow 634.3$ for cHMWK SP (KHNLGHGH) and $453.1 \rightarrow 640.6$ for IS (KHNL $\left.\left[{ }^{13} \mathrm{C}_{6}\right] \mathrm{GHGH}\right)$ in terms of the formation of the most abundant product ion. The detailed MRM parameters utilized in the QTrap6500 system were set as follows: collision energy of $25 \mathrm{eV}$, collision exit potential of $15 \mathrm{~V}$, declustering potential of $60 \mathrm{~V}$, entrance potential of $10 \mathrm{~V}$, curtain gas of 20 units, ion source gas 1 (GS1) of 50 units, ion source gas 2 (GS2) of 45 units, collision-activated 


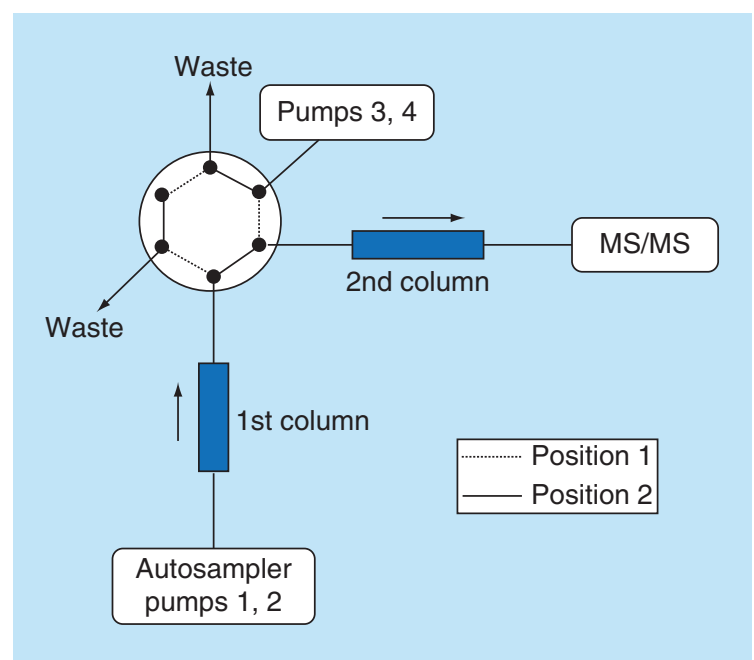

Figure 2. Schematic configuration of the 2D-LC-MS/ MS system. The six-port valve was placed initially in position 1 during the sample injection at which the column eluent was diverted to waste and peptides were gradient eluted from the first column through pumps 1 and 2 . The valve was switched to position 2 at $6.0 \mathrm{~min}$, and the LC fraction containing the SP and IS was directed to the second column. Shortly after complete elution of the analyte from the first column and transfer to the second column, the valve was switched back to position 1 at $7.3 \mathrm{~min}$. The trapped peptides were eluted from the second column by pumps 3 and 4, and were subsequently analyzed by mass spectrometry.

IS: Internal standard; SP: Surrogate peptide.

dissociation gas setting medium, dwell time $100 \mathrm{~ms}$, ion spray voltage of $5000 \mathrm{~V}$ and temperature of $550^{\circ} \mathrm{C}$.

\section{Preparation of calibration standards \& quality control samples}

The calibration standards were prepared by spiking appropriate amounts of the cHMWK stock solution or subsequent calibration standards to beagle plasma containing $10 \%(\mathrm{v} / \mathrm{v})$ of SCAT169 solution $(10 \times)$ as a surrogate matrix. Nominal concentrations of the calibrators were $200,400,1000,2500,10,000,15,000$, 18,000 and $20,000 \mathrm{ng} / \mathrm{ml}$, respectively. As a standard practice for validation of assay accuracy and precision, ten individual lots of human plasma (sodium citrate) from healthy subjects (collected and stored without treatment with SCAT 169) were pooled, and were immediately treated with the $10 \%(\mathrm{v} / \mathrm{v})$ SCAT169 solution prior to the preparation of the quality control (QC) samples. The endogenous level (EL) of cHMWK in the pooled healthy plasma was $2080 \mathrm{ng} /$ $\mathrm{ml}$, which was significantly higher than healthy plasma treated with SCAT 169 during sample collection and obviously due to the kallikrein-induced cleavage during sample collection and storage. The above pooled plasma sample was only used for the assay validation. It is difficult to distinguish EL from lower limit of quantitation (LLOQ) in regard to the high EL samples. The endogenous cHMWK concentration was taken into consideration during the calculation of $\mathrm{cHMWK}$ concentration of QC samples. The similar procedure was also utilized for the preparation of QC samples at five concentration levels, denoted as EL, LLQC $(\mathrm{EL}+200 \mathrm{ng} / \mathrm{ml})$, low quality control (LQC; EL +600 $\mathrm{ng} / \mathrm{ml}$ ), middle quality control (MQC; EL $+5000 \mathrm{ng} /$ $\mathrm{ml}$ ) and high quality control (HQC; EL + 15,000 ng/ $\mathrm{ml}$ ), covering the intended calibration curve range. Stock solution of IS at $10 \mu \mathrm{g} / \mathrm{ml}$ was prepared in $0.1 \%$ FA/acetonitrile 1:1 (v/v) and stored in polypropylene vials at $4^{\circ} \mathrm{C}$. The IS working solution $(30 \mathrm{ng} / \mathrm{ml})$ in $100 \mathrm{mM}$ ABC buffer was freshly prepared prior to sample preparation.

\section{Plasma collection}

Plasma samples were collected with institutional review board approval of the C1-INH-HAE investigator sites listed in the 'Acknowledgements' section with the blood collections procedures described in previous reports [19]. Each patient was previously confirmed to be C1-INHHAE and samples were collected between attacks (i.e., basal). Though the information on whether an individual patient had type I or type II was not obtained with these samples, it is known that both forms of C1-INH-HAE are due to a dysregulation of the contact system. Briefly, the SCAT-169-4.5/5 blood collection tube $(5.0 \mathrm{ml})$ was removed from refrigerator. Approximately $5 \mathrm{ml}$ of blood was drawn into the tube using the catheter with multisample luer adapter. Contents of the tube were not allowed to contact the stopper or end of the needle during procedure. Vacuum was exhausted prior to removing the tube from the nonpatient end of the needle. The blood was mixed with the tube additives by slowly inverting the tube eight- to ten-times immediately after blood collection and before centrifugation. The blood sample was centrifuged at $2000 \times g$ for $20 \mathrm{~min}$ at room temperature $\left(20-25^{\circ} \mathrm{C}\right)$ within $1 \mathrm{~h}$ of sample collection. The plasma samples were stored at $-70^{\circ} \mathrm{C}$ or colder until use. Informed consent forms were obtained from each healthy or patient subject.

\section{Sample preparation}

Protein pellet digestion

Samples were processed in a high-throughput 96-well plate format, following procedure reported previously by our lab with minor modification [37]. Briefly, aliquots of $25 \mu \mathrm{l}$ plasma samples (calibration standards, QCs, blanks or study samples) were transferred into a 96-well plate $(2 \mathrm{ml}$ capacity). The proteins were denatured by adding $2.5 \mu \mathrm{l}$ of $10 \%$ SDS, followed by vigorous vortex- 
Table 1. Signature peptides derived from digestion of $46 \mathrm{kDa}$ light chain with different enzymes.

\begin{tabular}{|c|c|c|c|c|}
\hline \multirow[t]{2}{*}{ Enzyme } & \multicolumn{2}{|c|}{ cHMWK peptide } & \multicolumn{2}{|r|}{ HMWK peptide } \\
\hline & AA positions & AA sequence & AA positions & AA sequence \\
\hline Chymotrypsin & $438-445$ & KHNLGHGH & $432-439$ & GHEKQRKH \\
\hline Glu-C & $438-448$ & KHNLGHGHKHE & $435-448$ & KQRKHNLGHGHKHE \\
\hline Asp-N & $438-449$ & KHNLGHGHKHER & $430-449$ & DWGHEKQRKHNLGHGHKHER \\
\hline
\end{tabular}

ing for 5 min on an Eppendorf Thermomixer (Eppendorf, NY, USA). Protein reduction was carried out by adding $5.0 \mu \mathrm{l}$ of $500 \mathrm{mM}$ DTT and subsequent incubation for $60 \mathrm{~min}$ at $37^{\circ} \mathrm{C}$ at 700 r.p.m. Plasma proteins were then precipitated by adding $0.7 \mathrm{ml}$ of $\mathrm{CH}_{3} \mathrm{OH}$ to each well followed by vigorous vortexing for $5 \mathrm{~min}$. After centrifugation at $2000 \times g$ for $10 \mathrm{~min}$, the $0.68 \mathrm{ml}$ of supernatant was removed and discarded by Tomtec liquid handler (Tomtec, CT, USA). The resulting protein pellet was washed with $0.7 \mathrm{ml}$ of methanol and after centrifugation, and $0.68 \mathrm{ml}$ of the supernatant was discarded gain. The plate was placed in a nitrogen blower to remove the remaining methanol. The protein pellets were resuspended in $500 \mu \mathrm{l}$ of $100 \mathrm{mM}$ ABC digestion buffer by vigorous vortexing for $5 \mathrm{~min}$. In total, $10 \mu \mathrm{l}$ of $500 \mathrm{mM}$ IAA and $25 \mu \mathrm{l}$ of IS working solution (30 ng/ $\mathrm{ml})$ were added, mixed well and kept in the dark for $30 \mathrm{~min}$ at 600 r.p.m. for alkylation. To the protein suspension was added $10 \mu \mathrm{l}$ of $8.0 \mathrm{mg} / \mathrm{ml}$ freshly prepared chymotrypsin solution in $100 \mathrm{mM}$ ABC buffer (1:20 $\mathrm{E} / \mathrm{S})$. The proteolytic digestion was carried out at $50^{\circ} \mathrm{C}$ at 1000 r.p.m. vortexing for $3 \mathrm{~h}$ in the dark. The samples were acidified by adding $10 \mu \mathrm{l}$ of formic acid, followed by vigorous vortexing for $5 \mathrm{~min}$, to quench the digestion.

\section{Peptide enrichment by solid phase extraction}

The acidified peptide mixture was centrifuged at 3000 $\times g$ for $10 \mathrm{~min}$. The supernatant $(460 \mu \mathrm{l})$ was transferred to a Waters MCX plate (30 $\mu \mathrm{m}, 10 \mathrm{mg}$, Waters) preconditioned sequentially with $1 \mathrm{ml}$ of $\mathrm{CH}_{3} \mathrm{CN}$ and $1 \mathrm{ml}$ of $1.0 \%$ FA. After sequentially washing with $900 \mu \mathrm{l}$ of $1.0 \% \mathrm{FA}, 900 \mu \mathrm{l}$ of water and $900 \mu \mathrm{l}$ of $\mathrm{CH}_{3} \mathrm{OH}$, the peptides were eluted by $600 \mu \mathrm{l}$ of $\mathrm{CH}_{3} \mathrm{OH}$ containing $5.0 \%$ ammonia hydroxide (v/v) and collected in a clean 96-well collection plate. The eluent was evaporated to dryness under a steady stream of nitrogen at $37^{\circ} \mathrm{C}$. The sample was reconstituted in $100 \mu \mathrm{l}$ of reconstitution solution $\left(\mathrm{CH}_{3} \mathrm{OH}\right.$ :water $[10: 90 ; \mathrm{v} / \mathrm{v}]$ containing $1.0 \%$ HFBA $[v / v])$. Then, each sample $(20 \mu \mathrm{l})$ was injected into the ion-pair 2D-LC-MS/MS system.

\section{Method validation}

Validation followed the FDA guidelines for bioanalytical method validation and white paper $[38,39]$. The method was validated for linearity, accuracy, precision, matrix effects, pellet digestion efficiency and solid phase extraction (SPE) efficiency. Calibration curves were constructed utilizing peak area ratios of SP to IS with a weighted $\left(1 / \mathrm{x}^{2}\right)$ least-squares linear regression analysis. Accuracy (expressed as percentage error) and precision (expressed as percentage relative standard deviation) were calculated at five levels of QC samples (EL, EL + 200 ng/ml, EL + 600 ng/ml, EL + 5000 ng/ $\mathrm{ml}$ and $\mathrm{EL}+15,000 \mathrm{ng} / \mathrm{ml})$. The intraday accuracy and precision were analyzed using six replicates of each QC level every day. This process was repeated threetimes to determine the interday accuracy and precision over 3 days. Mean accuracy and precision statistics for QC samples were calculated using Microsoft Excel.

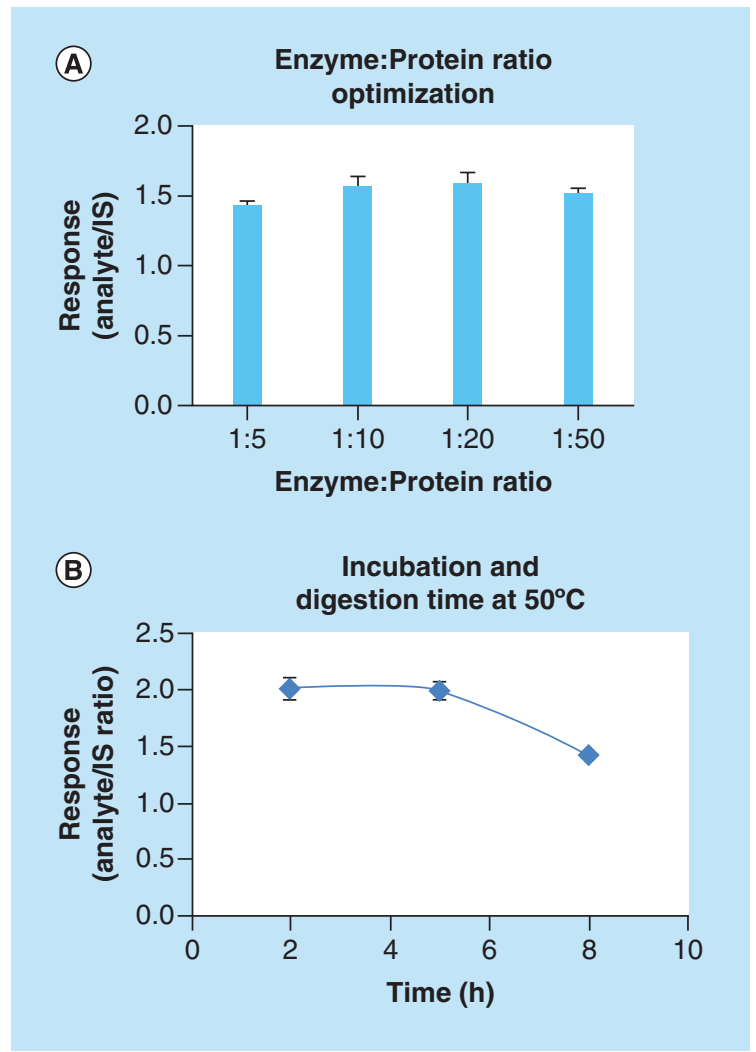

Figure 3. Optimization of cHMWK pellet digestion $(10 \mu \mathrm{g} / \mathrm{ml}$ in plasma; $\mathbf{n}=3)$ by chymotrypsin.

(A) enzyme:protein ratio optimization; (B) response over digestion time at $50^{\circ} \mathrm{C}$ and $\mathrm{IS}: 25 \mathrm{ng} / \mathrm{ml}$.

IS: Internal standard. 


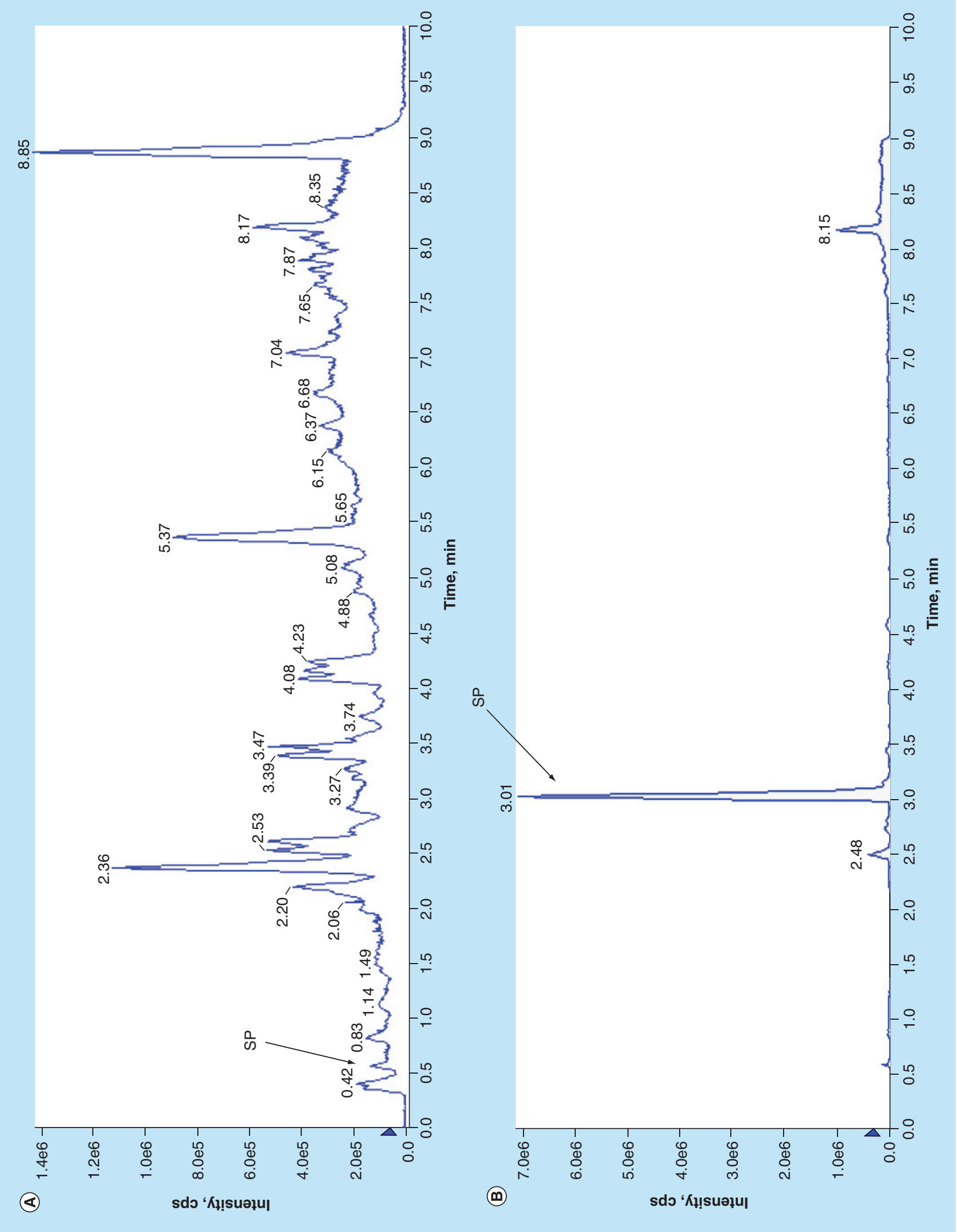


Figure 4. Ion-pair reversed-phase LC improves retention of surrogate peptide and reduces ion suppression (see facing page). CHMWK $(100 \mu \mathrm{g} / \mathrm{ml})$ plasma extract was injected to 1D-LC-MS system using selected ion monitoring (SIM: 450.2) and an Agilent Metasil AQ C18 Column (2.0 mm $\times 100 \mathrm{~mm}, 5 \mu \mathrm{m})$. (A) Without ionpair reagents: mobile phase $A$ was $0.1 \%$ of $F A(v / v)$ in water and mobile phase $B$ was $0.1 \%$ of $F A(v / v)$ in $\mathrm{CH}_{3} \mathrm{OH}_{\text {; }}$ injection solution was $\mathrm{CH}_{3} \mathrm{OH}$ : water $(5: 95$; v/v) containing $0.1 \%$ of FA (v/v). (B) With ion-pair reagents: mobile phase $A$ was $0.1 \%$ of TFA (v/v) in water and mobile phase $B$ was $0.1 \%$ of TFA $(\mathrm{v} / \mathrm{v})$ in $\mathrm{CH}_{3} \mathrm{OH}$; injection solution was $\mathrm{CH}_{3} \mathrm{OH}$ :water $(10: 90 ; \mathrm{v} / \mathrm{v})$ containing $1.0 \%$ of HFBA (v/v). The same graduate elution conditions were utilized in (A) and (B): $0 \mathrm{~min} / 1.0 \% \mathrm{~B}, 0.5 \mathrm{~min} / 1.0 \% \mathrm{~B}, 5.0 \mathrm{~min} / 50.0 \% \mathrm{~B}, 7.0 \mathrm{~min} / 90.0 \% \mathrm{~B}, 8.0 \mathrm{~min} / 90.0 \% \mathrm{~B}, 8.1 \mathrm{~min} / 1.0 \% \mathrm{~B}$ and $10.0 \mathrm{~min} / 1.0 \% \mathrm{~B}$ at a flow rate of $0.45 \mathrm{ml} / \mathrm{min}$. Injection volume: $20 \mu \mathrm{l}$.

FA: Formic acid; HFBA: Heptafluorobutyric acid; TFA: Trifluoroacetic acid.

The criteria for intraday or interday accuracy and precision were $\leq \pm 25 \%$ for LLOQ and $\leq \pm 20 \%$ for LQC, MQC and HQC. The SPE extraction efficiency was determined using SP-spiked digestion solution of the blank beagle plasma samples $(n=5)$ at the concentrations of $1.5 \mathrm{ng} / \mathrm{ml}$ of SP. SPE extraction efficiency was determined by dividing the peak area of SP spiked before SPE extraction by the peak area of a SP sample spiked after extraction at equal concentration in the same matrix. Matrix effect evaluations were performed by assessing the accuracy of LQC samples utilizing six independent lots of human plasma fortified to the LQC samples. Plasma matrix stability of cHMWK after freeze-thaw (4 cycles) or bench-top stability at $4^{\circ} \mathrm{C}(8 \mathrm{~h})$ as well as processed sample stability in an autosampler $(48 \mathrm{~h})$ were also assessed.

\section{Statistics}

Student's t-test for unpaired values and receiver operator curve were utilized to evaluate the statistical significance of the differences between healthy subjects and C1-INH-HAE patients and p-value $(<0.05)$ was considered statistically significant.

\section{Results \& discussion}

\section{LC-MS strategy \& SP selection}

HMWK and cHMWK share the same amino acid sequence minus the presence of bradykinin in cHMWK, where the different C-terminal peptides of the heavy chains and the $\mathrm{N}$-terminal peptides of the light chains can differentiate the two proteins (Figure 1). Plasma kallikrein cleaves HMWK at site $\mathrm{Lys}_{380}-\mathrm{Arg}_{381}$ and at site $\mathrm{Ser}_{390}-\mathrm{Ser}_{644}$ to generate bradykinin as well as a heterogeneous heavy chain and a $56 \mathrm{kDa}$ light chain. The $56 \mathrm{kDa}$ light chain in cHMWK is further truncated both in vitro and in vivo to form a stable $46 \mathrm{kDa}$ light chain ( $\mathrm{Lys}_{438}{ }^{-}$ $\mathrm{Ser}_{644}$ ) (Figure 1) [40]. As the $46 \mathrm{kDa}$ cHMWK is the final cleavage product and is presumably more stable, we measured $46 \mathrm{kDa}$ isoform as a potential biomarker of contact system activation. For this purpose, experimental conditions were optimized in order to measure peptide derived from $\mathrm{N}$-terminus of $46 \mathrm{kDa}$ light chain as a cHMWK surrogate. Trypsin and Lys-C digestion did not generate the specific peptide to differentiate
HMWK and cHMWK. In contrast, chymotrypsin, Glu-C and Asp-N digestion all successfully generated unique peptides (Table 1). Chymotrypsin was selected for assay development as the resulting peptide KHNLGHGH from the digestion by chymotrypsin possessed the excellent MS responses and the enzyme cost is more manageable compared with Glu-C and Asp-N. Although chymotrypsin is less specific, which is usually not the first option for protein quantitation, we found the digestion at the desired site is highly specific as no other $\mathrm{N}$-terminal peptides derived from the $46 \mathrm{kDa}$ protein were identified. The peptide sequence was further blasted against the protein database to ensure it has no overlap with the hypothetical chymotrypsin peptides derived from other human proteins except HMWK.

In previous reports, western blotting has been a method of choice to measure the relative abundance of the total HMWK and cHMWK as a CI-INH-HAE biomarker [12,24]. In contrast, our LC-MS assay measures the absolute quantitation of cHMWK (without normalized to total HMWK) with an aim to explore whether cHMWK level alone is correlated with C1-INH-HAE disease.

\section{Protein pellet digestion}

One challenge for LC-MS-based protein quantitation is to enrich target protein biomarkers in the presence of highly abundant endogenous proteins in biological samples. To improve assay sensitivity for target protein, IP in conjunction with LC-MS/MS is widely used [29-31,41]. A variety of commercially available anti-HMWK, antilight chain and antiheavy chain antibodies were assessed as IP reagents but none was able to efficiently pull down the targeted proteins (data not shown). Recently, direct pellet digestion of serum proteins by proteases following $\mathrm{CH}_{3} \mathrm{OH}$ precipitation has been described in several papers [42-45]. This 'reagent-free' approach was capable of simplifying sample manipulation and cleaning up salts, protease inhibitors and other hydrophilic components in serum to improve the digestion. Efficient and reproducible pellet digestion by chymotrypsin is a critical step to ensure the accuracy and precision of the $\mathrm{CHMWK}$ assay. We further 


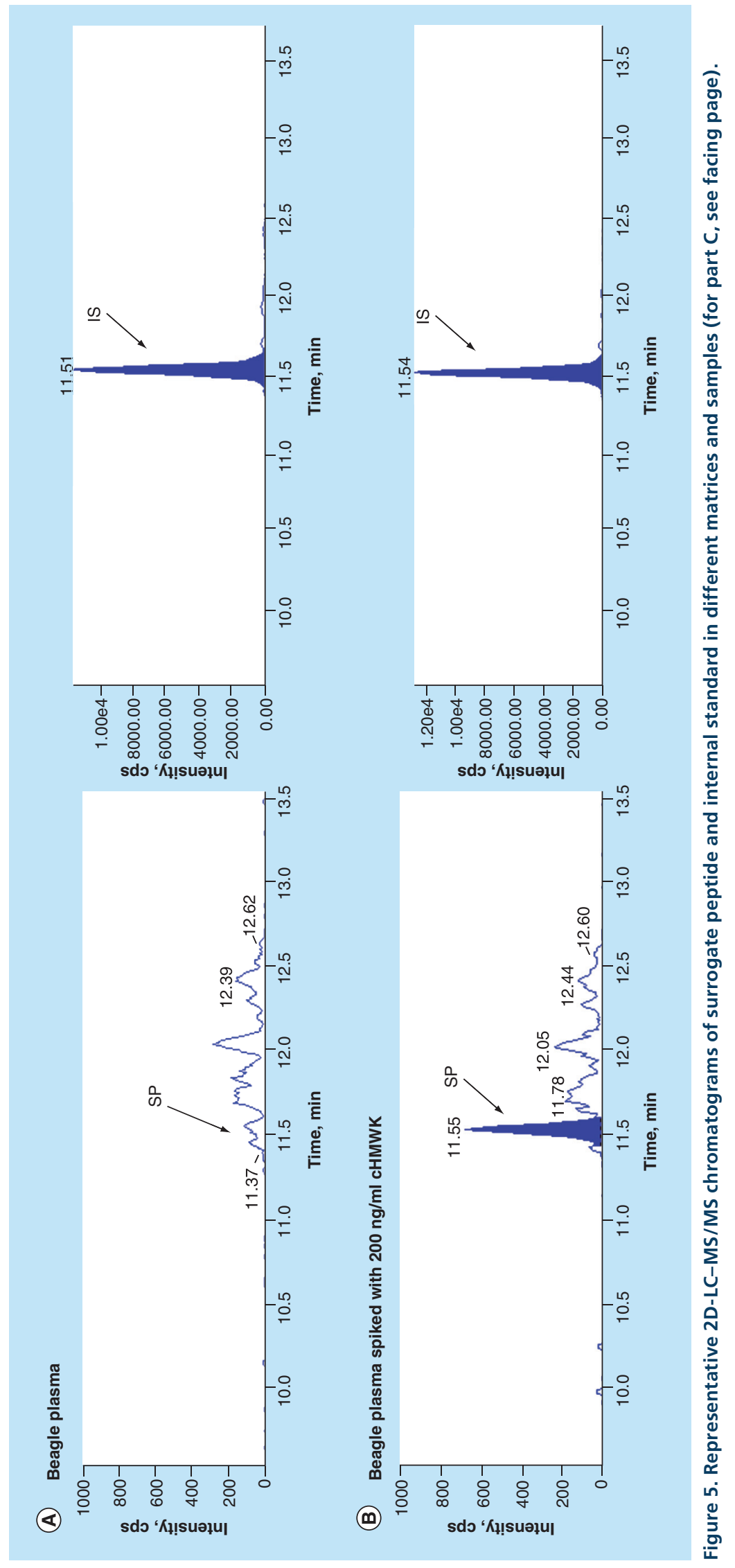




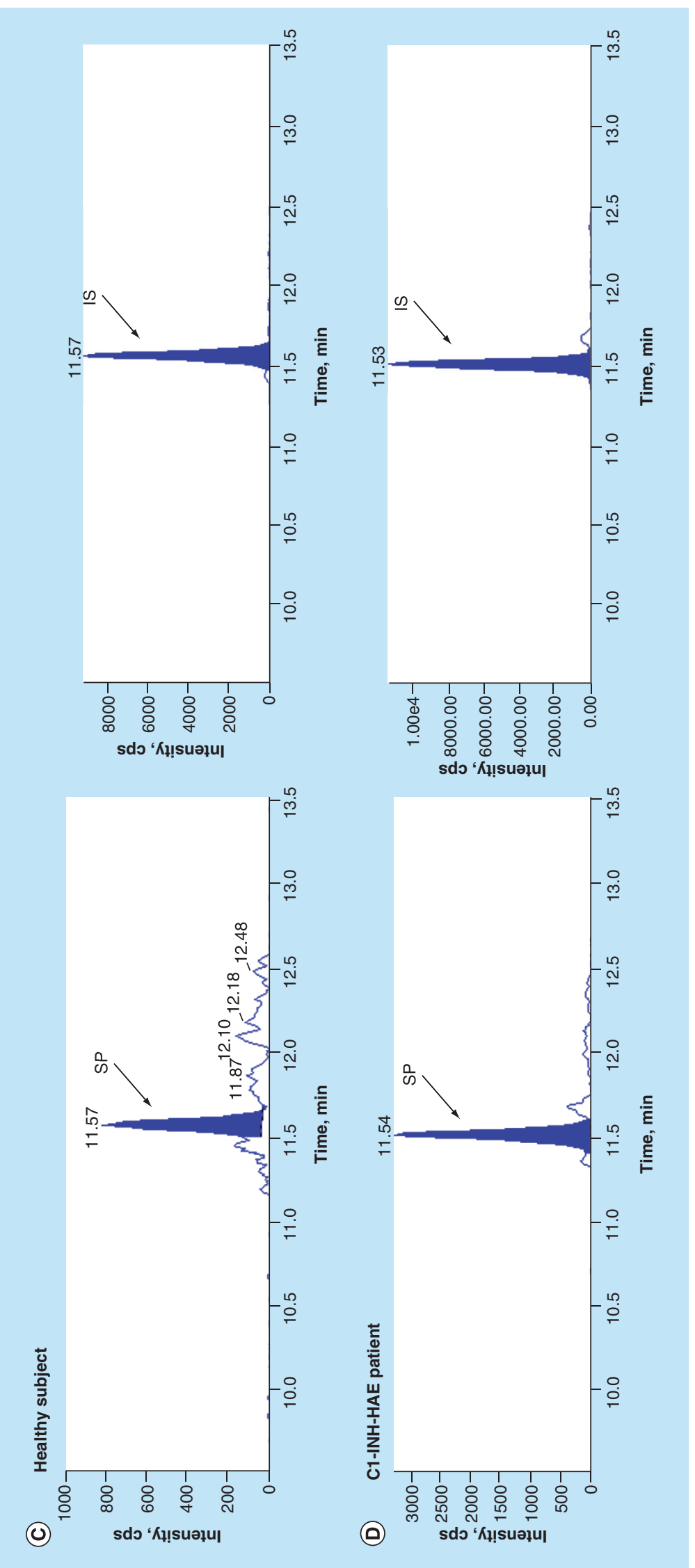




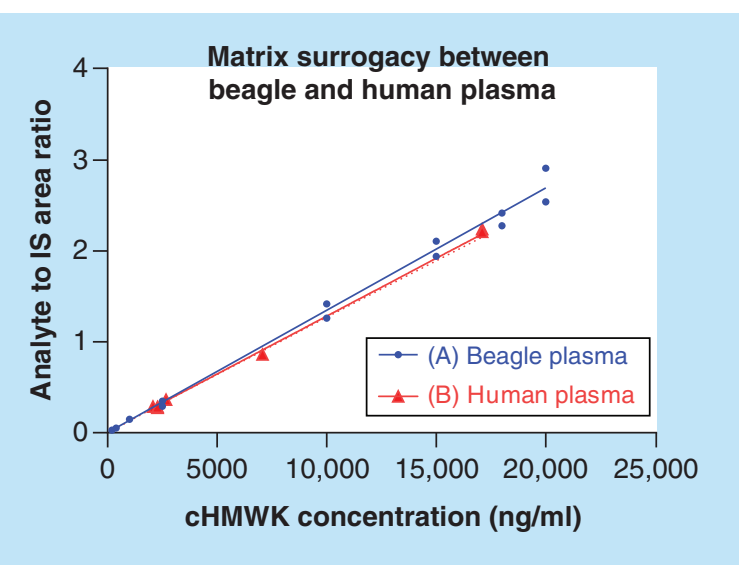

Figure 6. Calibration curves in beagle and human plasma. (A) beagle plasma $Y=0.000135 X+0.000275$; $\mathrm{R}^{2}=0.9915$ and $(\mathrm{B})$ human plasma

$Y=0.000126 X+0.00168 ; R^{2}=0.9927$ to demonstrate matrix surrogacy. Each concentration level included duplicate samples.

optimized the pellet digestion procedures previously described [37] by using SDS (0.1\%) to completely denature proteins to facilitate the enzyme digestion. DTT as a reducing agent minimized background in the subsequent LC-MS cHMWK assay (data not shown). After $\mathrm{CH}_{3} \mathrm{OH}$ precipitation, SDS, reducing agent, small MW proteinase inhibitors in SCAT169, phospholipids and other endogenous soluble species were easily removed from the protein pellets.

The protein-enzyme ratio and digestion temperature were optimized, aiming to enhance digestion efficiency and/or shorten the digestion time. In our experiments, $3 \mathrm{~h}$ digestion at $50^{\circ} \mathrm{C}$ with a chymotrypsin: protein ratio of $1: 20$ gave rise to reproducible results with improved $S / \mathrm{N}$ ratio (Figure $3 A$ \& B). In contrast, digestion at $37^{\circ} \mathrm{C}$ overnight would compromise digestion efficiency (data not shown). The SDS and $\mathrm{CH}_{3} \mathrm{OH}$ denaturation in conjunction with DTT reduction facilitated the dissociation of cHMWK from endogenous binding proteins and promoted the chymotrypsin digestion efficiency of the cHMWK. As justified from the relative peak areas of the SP/IS, the overall cHMWK recovery combining $\mathrm{CH}_{3} \mathrm{OH}$ crash and digestion steps were $57.5 \pm 1.7 \%$ at $10 \mu \mathrm{g} / \mathrm{ml}$ $(\mathrm{n}=5)$ in SCAT169 human plasma.

\section{Chromatographic separation of SP}

Human plasma contains thousands of proteins with a huge dynamic range of expression. Upon pellet digestion, the proteins were chopped into hundreds of thousands of peptides, many of which would co-elute and interfere with the analyte measurement under the routine chromatographic conditions. In addition, the SP (KHNLGHGH) is a short and very hydrophilic peptide, limiting its retention on the reversed phase $\mathrm{C}_{18}$ column without ion-pair reagent in the mobile phase. As a matter of fact, after peptide sample extracted from the pellet digestion of $100 \mu \mathrm{g} / \mathrm{ml} \mathrm{cHMWK}$ spiked in human plasma was injected to a $1 \mathrm{D}-\mathrm{LC}-\mathrm{MS} / \mathrm{MS}$ system using the $\mathrm{C}_{18}$ column in mobile phases containing $0.1 \%$ of $\mathrm{FA}$ $(\mathrm{v} / \mathrm{v})$, the signal of the SP was barely detectable due to the poor retention of the peptide and significant ion suppression (Figure 4A). Different ion paring agents such as $0.1 \%$ TFA and $0.1 \%$ HFBA were included in the mobile phases aiming to enhance the retention. TFA was able to improve ion signal, but peptide still eluted out of the column too soon. An opposite effect was observed when HFBA was utilized. In order to obtain sufficient analyte retention yet without significant ion suppression, we included $1 \%(\mathrm{v} / \mathrm{v})$ of HFBA in the injection solution while maintained $0.1 \%$ of TFA $(\mathrm{v} / \mathrm{v})$ in the mobile phase, the combination leading to much improved chromatographic retention as well as the sensitivity enhancement (Figure 4B). Obviously high concentration of HFBA in injection solution significantly increased the retention of SP on the first LC column, and by the time SP was eluted from the second column, the HFBA was already washed out, therefore the ion suppression is no longer an issue. To our best knowledge, it was the first time that

\begin{tabular}{|c|c|c|c|c|c|c|}
\hline \multirow{2}{*}{$\begin{array}{l}\text { Theoretical } \\
\text { concentration }(\mathrm{ng} / \mathrm{ml})\end{array}$} & \multicolumn{3}{|c|}{ Intraday } & \multicolumn{3}{|c|}{ Interday } \\
\hline & $\begin{array}{l}\text { Measured concentration } \\
\pm \mathrm{SD}(\mathrm{ng} / \mathrm{ml})\end{array}$ & RSD (\%) & RE (\%) & $\begin{array}{l}\text { Measured concentration } \\
\pm S D(n g / m l)\end{array}$ & RSD (\%) & RE (\%) \\
\hline 2080 (EL) & $1970 \pm 162$ & 8.2 & -5.3 & $2040 \pm 176$ & 8.6 & -1.9 \\
\hline 2280 (LLQC) & $1980 \pm 56$ & 2.8 & -13.2 & $2000 \pm 123$ & 6.2 & -12.3 \\
\hline 2680 (LQC) & $2420 \pm 303$ & 12.5 & -9.7 & $2310 \pm 293$ & 12.7 & -13.8 \\
\hline 7080 (MQC) & $6860 \pm 509$ & 7.4 & -3.1 & $6490 \pm 594$ & 9.1 & -8.3 \\
\hline 17,100 (HQC) & $17,200 \pm 367$ & 2.1 & 0.6 & $16,500 \pm 957$ & 5.8 & -3.5 \\
\hline
\end{tabular}




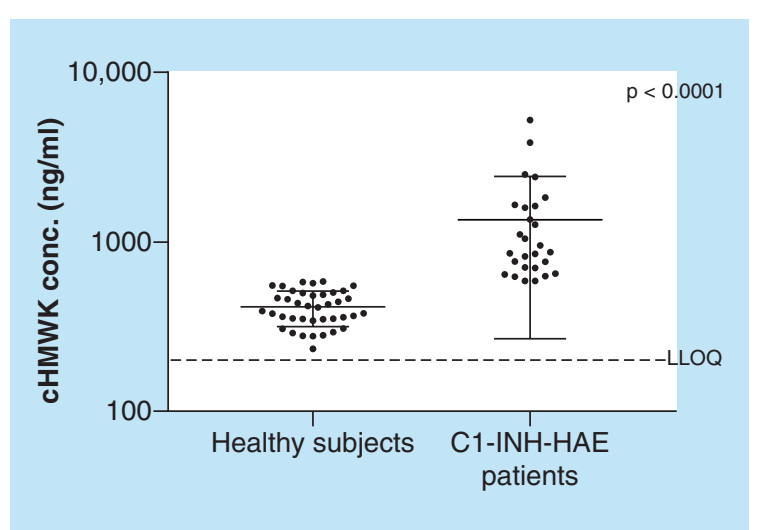

Figure 7. cHMWK plasma level in healthy subjects $(415.2 \pm 98.2 \mathrm{ng} / \mathrm{ml}[\mathrm{n}=39])$ and C1-INH-HAE patients $(1359 \pm 1090 \mathrm{ng} / \mathrm{ml}[\mathrm{n}=27])$.

two ion-pair reagents were utilized in tandem to retain extremely polar peptide on reversed-phase column yet maintain the assay sensitivity.

Although, the 2D-LC-MS/MS has been widely utilized in large scale protein identification and global protein quantification in proteomics field, only recently has it gained attention as a valuable approach to targeted protein quantitation in regulated study [37,46]. The system enriches the target peptide on the column and circumvents the need for immunoaffinity reagents, yet reaches low nanogram/ $\mathrm{ml}$ sensitivity and maintains high throughput. In contrast to global proteomic identification aiming to identify as many peptides as possible, the targeted quantitation only focuses on the specific SP [37]. The narrow valve switch window $(1.3 \mathrm{~min})$ significantly reduced the total number of peptides pouring onto the second column, greatly enriching the targeted peptide and minimizing the interferences by the coeluting peptides [37,47]. The 2D-LC-MS/ MS described here offered LLOQ of $200 \mathrm{ng} / \mathrm{ml}$ for cHMWK protein, at least fivefold increase in comparison with 1D-LC-MS/MS (LLOQ: $1000 \mathrm{ng} / \mathrm{ml}$; data not shown).

\section{Fit-for-purpose assay validation results}

\section{Surrogate matrix \& calibration curve}

A fit-for-purpose validation was performed for the cHMWK LC-MS assay [30,48]. It is a common challenge for biomarker analysis to find an appropriate matrix for the preparation of standard curve. Ideally, the matrix does not contain the SP sequence or generate irrelevant MRM responses at the retention time window of SP, yet it should be identical or similar to the sample matrix based on digestion efficiency, ionization effects and SPE extraction efficiency. Screening of human serum showed that endogenous cHMWK concentration is highly variable and will interfere with the assay. Therefore, we decided to use plasma from another species as a surrogate. In the preliminary study, cyno, mouse, rat and beagle plasma were evaluated and only beagle plasma gave rise to clean background and insignificant interferences to the SP signal (Figure 5A, Graph 1). The parallelism of the surrogate matrix (beagle plasma) and sample matrix (human plasma) was demonstrated by comparing the slope difference of the two calibration curves prepared in two matrices. The relative error (RE) of the slope difference is $6.9 \%$, demonstrating a good surrogacy of the beagle plasma because the pellet digestion efficiency, ionization effects and extraction recovery are similar to human plasma (Figure 6). The good linear response by interday calibration curves was demonstrated over the concentration range of 200 $20,000 \mathrm{ng} / \mathrm{ml}$ in human plasma $(\mathrm{n}=3)$. The Pearson correlation $\left(\mathrm{R}^{2}\right) \pm \mathrm{SD}$ was $0.9955 \pm 0.00115$. The slope $\pm \mathrm{SD}$ of calibration curves was $0.000147 \pm 0.0000289$. RE typically ranged from -13.1 to $14.0 \%$ between backcalculated standard concentrations and nominal values. Representative chromatograms obtained from surrogate plasma in the LLOQ standard $(200 \mathrm{ng} / \mathrm{ml})$ are shown in Figure 5B, Graph 1. There were no significant interfering peaks from endogenous compounds observed at the retention time of the SP in blank surrogate matrix.

\section{Validation precision \& accuracy}

Five QC levels (EL, LLOQ, LQC, MQC and HQC), each in six replicates, were evaluated in three consecutive runs to assess intrarun and inter-run accuracy and precision. As demonstrated in Table 2, the intraday and interday precision ranges from 2.1 to $12.5 \%$ and 5.8 to $12.7 \%$ respectively. The intraday and interday accuracy ranges from -13.2 to $0.6 \%$ and -13.8 to $-3.5 \%$. All the calibration standards and the QCs passed the acceptance criteria $(\leq \pm 20.0 \%)$ (Table 2 ).

\section{SPE extraction efficiency, matrix effects \& matrix stability}

SPE was utilized to enrich and desalt the peptides prior to LC-MS/MS. SPE extraction efficiency was assessed by dividing the peak area of SP spiked before SPE extraction by the peak area of the same amount of SP spiked after extraction. Since reversed-phase cartridge did not retain the SP, strong cation exchange cartridge (Waters MCX) was utilized. The extraction efficiency of SP using the strong cation exchange cartridge was $52.6 \pm 2.64 \%(n=5)$. Six independent lots of human plasma were fortified to the LQC samples. Matrix effect evaluations were conducted by assessing the accuracy of the six individual LQC samples. The results demonstrated all of the QC samples met the accuracy criteria $(\leq \pm 20.0 \%)$, and there was no significant matrix effects for the cHMWK assay. 
Matrix stability of macromolecules, including protein biomarkers, is a critical validation parameter. The analyte cHMWK is an enzymatic product generated from cleavage of the HMWK by endogenous serine proteinase plasma kallikrein, and can be constantly generated in vitro during plasma sample collection, storage and sample preparation if proteolytic activity of the plasma kallikrein is not inhibited [6,25]. SCAT169 reagent contains a variety of different protease inhibitors aiming to halt the kallikrein activity and thus to stabilize HMWK [49]. Freeze-thaw (4 cycles) or benchtop stability at $4^{\circ} \mathrm{C}(8 \mathrm{~h})$ as well as processed sample stability in an autosampler $(48 \mathrm{~h})$ were also assessed. As shown in Supplementary Table 1, the RE (\%) of the stability test results ranged from -9.0 to $-7.1 \%$, which were well within the RE\% acceptance criteria. The data in Supplementary Table 1 demonstrated that the cHMWK was stable in plasma treated with SCAT169 inhibitor.

Analysis of cHMWK in healthy individuals \& C1INH-HAE patients

The concentration of $46 \mathrm{kDa}$ cHMWK in plasma from 39 healthy controls and 27 C1-INH-HAE patients were tested utilizing the described method. All SCAT169 plasma samples were collected without any special treatment (dialysis, deproteination and delipidation). C1-INH-HAE patient demographics were shown in Supplementary Table 2. Assay sensitivity was sufficient for measuring $46 \mathrm{kDa}$ cHMWK levels in all subjects (39 healthy controls and 27 C1-INH-HAE patients). Representative chromatograms for monitoring cHMWK level in healthy subjects and C1-INH-HAE patients are shown in Figure $5(\mathrm{C} 1$ and $\mathrm{D} 1)$. The concentration of cHMWK in plasma was $415.2 \pm 98.2 \mathrm{ng} /$ $\mathrm{ml}(\mathrm{n}=39)$ for healthy subjects and $1359 \pm 1090 \mathrm{ng} /$ $\mathrm{ml}(\mathrm{n}=27)$ for C1-INH-HAE patients, respectively. Hence, plasma levels of $46 \mathrm{kDa}$ cHMWK in the
C1-INH-HAE patients were significantly higher than that in healthy subjects (Figure 7; $\mathrm{p}<0.0001$ ). In addition, receiver operator curve in Supplementary Figure 3 supports above claim as well (the area under the curve is 1.0 and $p<0.0001$ ). These results are consistent with the previous reports that patients with C1-INH-HAE exhibit a dysregulated contact system between attacks and thus exhibit elevated cHMWK and bradykinin in plasma [12,14-17,24]. Overall, we have demonstrated that the reagent-free LC-MS assay is able to accurately measure the plasma $46 \mathrm{kDa}$ cHMWK concentration in the presence of a large amount of endogenous HMWK. Consistent with previous observations [12], our data from a limited number of healthy subjects and C1-INH-HAE patients suggest that the concentration of $46 \mathrm{kDa}$ cHMWK alone can differentiate the two groups. However, additional investigations are required to validate the utility of $46 \mathrm{kDa}$ cHMWK as a clinical biomarker for C1-INH-HAE diagnosis and/or therapeutic responses.

\section{Conclusion}

We presented a novel LC-MS assay for quantitative measurement of the $46 \mathrm{kDa}$ cHMWK in human plasma using a surrogate matrix. The assay is robust, specific and sensitive, enabling quantitation of the analyte in both healthy subjects and C1-INH-HAE patients. Most notably, the described assay does not need the time-consuming production and characterization of specific antibody reagents to distinguish cHMWK and HMWK. Our preliminary data on a limited sample size shows that the $46 \mathrm{kDa}$ cHMWK, the final product of the plasma kallikrein proteolytic digestion, allows differentiation of C1-INH-HAE patients and healthy control group. Further studies are needed to validate its potential use as a C1-INH-HAE biomarker.

Summary points

Background

- Although CHMWK has been proposed as a potential biomarker for C1-INH-HAE, it remains challenging to quantify the analyte due to the interference from its high-molecular-weight kininogen precursor.

Experimental

- A novel ion-pair 2D-LC-MS/MS assay combined with pellet digestion using chymotrypsin to measure $46 \mathrm{kDa}$ cHMWK in human plasma.

- Ion-pair 2D-LC-MS/MS techniques utilizing a narrow valve switch window (1.3 min) significantly reduced the background and interference.

Results

- The technique was successfully applied to the determination of cHMWK in healthy subjects and C1-INH-HAE patients. The ion-pair 2D-LC-MS/MS techniques enhanced the sensitivity by at least fivefold in comparison with 1D-LC-MS/MS.

Conclusion

- A robust, reagent-free LC-MS assay is developed for the quantitation of $46 \mathrm{kDa}$ cHMWK, allowing differentiation of C1-INH-HAE patients and healthy subjects. 


\section{Future perspective}

The novel LC-MS/MS assay described here takes advantage of the unique peptide sequence resulting from the chymotrypic digestion of the cHMWK in the presence of a high abundance of HMWK. The assay circumvents the use of immunoaffinity reagent to capture the target protein and is truly 'reagent-free'. This assay can easily be implemented as an alternative to the immunoassay where antibody reagents are not readily available. Further studies should be directed in larger populations to validate the utility of the $46 \mathrm{kDa}$ cHMWK as a potential biomarker for disease diagnosis, progress and therapeutic efficacy for C1-INH-HAE. In addition, a follow-up study can be set up to investigate whether the assay can detect elevated cHMWK in plasma from HAE patients with normal C1-INH, a condition that has not been firmly established to be mediated by a dysregulation in contact system activation. In addition, an isotopically labeled cHMWK protein can be introduced as an IS to minimize the variability in the sample preparation if its clinical usage is further proven in large scale of patient populations.

\section{Supplementary data}

To view the supplementary data that accompany this paper, please visit the journal website at: www.future-science.com/doi/suppl/10.4155/bio-2017-0105

\section{References}

1 Zuraw BL, Christiansen SC. HAE pathophysiology and underlying mechanisms. Clin. Rev. Allergy Immunol. 51(2), 216-229 (2016).

2 Zeerleder S. C1-inhibitor: more than a serine protease inhibitor. Semin. Thromb. Hemost. 37(4), 362-374 (2011).

3 Davis AE, 3rd, Lu F, Mejia P. C1 inhibitor, a multifunctional serine protease inhibitor. Thromb. Haemost. 104(5), 886-893 (2010).

4 Cicardi M, Beretta A, Colombo M, Gioffre D, Cugno M, Agostoni A. Relevance of lymphoproliferative disorders and of anti-C1 inhibitor autoantibodies in acquired angiooedema. Clin. Exp. Immunol. 106(3), 475-480 (1996).

5 Kaplan AP, Greaves MW. Angioedema. J. Am. Acad. Dermatol. 53(3), 373-388; quiz 389-392 (2005).

6 Nussberger J, Cugno M, Amstutz C, Cicardi M, Pellacani A, Agostoni A. Plasma bradykinin in angio-oedema. Lancet 351(9117), 1693-1697 (1998).

7 Agostoni A, Cicardi M. Hereditary and acquired C1inhibitor deficiency: biological and clinical characteristics in 235 patients. Medicine (Baltimore) 71(4), 206-215 (1992).

8 Colman RW, Schmaier AH. Contact system: a vascular biology modulator with anticoagulant, profibrinolytic, antiadhesive, and proinflammatory attributes. Blood $90(10)$, 3819-3843 (1997).

9 Berrettini M, Lammle B, White T et al. Detection of in vitro and in vivo cleavage of high molecular weight kininogen

\section{Acknowledgements}

HAE plasma was collected by the following biomarker study investigators: C Akin (Brigham and Womens Hospital), J Anderson (Clinical Research Center of Alabama, Alabama Allergy \& Asthma Center), A Banerji (Massachusetts General Hospital), J Bernstein (University of Cincinnati), E Brooks (UT Health Science Center at San Antonio), P Busse (Mount Sinai School of Medicine), M Cicardi (University of Milan), H Li (Institute for Asthma and Allergy, MD, USA), D McNeil (Columbus, $\mathrm{OH}$, USA), L Schwartz and J Wedner (Washington University School of Medicine).

\section{Financial \& competing interests disclosure}

All authors are full-time employees of Shire and own stock. Shire funded the study. The authors have no other relevant affiliations or financial involvement with any organization or entity with a financial interest in or financial conflict with the subject matter or materials discussed in the manuscript apart from those disclosed.

No writing assistance was utilized in the production of this manuscript.

\section{Open access}

This work is licensed under the Attribution-NonCommercialNoDerivatives 4.0 Unported License. To view a copy of this license, visit http://creativecommons.org/licenses/by-nc$n d / 4.0 /$

in human plasma by immunoblotting with monoclonal antibodies. Blood 68(2), 455-462 (1986).

10 Cugno M, Cicardi M, Bottasso B et al. Activation of the coagulation cascade in C1-inhibitor deficiencies. Blood 89(9), 3213-3218 (1997).

11 Mori K, Nagasawa S. Studies on human high molecular weight (HMW) kininogen. II. Structural change of HMW kininogen by the action of human plasma kallikrein. J. Biochem. 89(5), 1465-1473 (1981).

12 Baroso R, Sellier P, Defendi F et al. Kininogen cleavage assay: diagnostic assistance for kinin-mediated angioedema conditions. PLoS ONE 11(9), e0163958 (2016).

13 Couture R, Blaes N, Girolami JP. Kinin receptors in vascular biology and pathology. Curr. Vasc. Pharmacol. 12(2), 223-248 (2014).

14 Gainer JV, Morrow JD, Loveland A, King DJ, Brown NJ. Effect of bradykinin-receptor blockade on the response to angiotensin-converting-enzyme inhibitor in normotensive and hypertensive subjects. N. Engl. J. Med. 339 (18), 1285-1292 (1998).

15 Leeb-Lundberg LM, Marceau F, Muller-Esterl W, Pettibone DJ, Zuraw BL. International union of pharmacology. XLV. Classification of the kinin receptor family: from molecular mechanisms to pathophysiological consequences. Pharmacol. Rev. 57(1), 27-77 (2005).

16 Longhurst $\mathrm{H}$, Cicardi $\mathrm{M}$. Hereditary angio-oedema. Lancet 379(9814), 474-481 (2012). 
17 Schmaier AH. Assembly, activation, and physiologic influence of the plasma kallikrein/kinin system. Int. Immunopharmacol. 8(2), 161-165 (2008).

18 Banerji A, Busse P, Shennak M et al. Inhibiting plasma kallikrein for hereditary angioedema prophylaxis. N. Engl. J. Med. 376(8), 717-728 (2017).

19 Chyung Y, Vince B, Iarrobino R et al. A Phase 1 study investigating DX-2930 in healthy subjects. Ann. Allergy. Asthma. Immunol. 113(4), 460-466 e462 (2014).

20 Kenniston JA, Faucette RR, Martik D et al. Inhibition of plasma kallikrein by a highly specific active site blocking antibody. J. Biol. Chem. 289(34), 23596-23608 (2014).

21 Cugno M, Zanichelli A, Bellatorre AG, Griffini S, Cicardi M. Plasma biomarkers of acute attacks in patients with angioedema due to C1-inhibitor deficiency. Allergy 64(2), 254-257 (2009).

22 Schapira M, Silver LD, Scott CF et al. Prekallikrein activation and high-molecular-weight kininogen consumption in hereditary angioedema. N. Engl. J. Med. 308(18), 1050-1053 (1983).

23 Kaufman N, Page JD, Pixley RA, Schein R, Schmaier AH, Colman RW. Alpha 2-macroglobulin-kallikrein complexes detect contact system activation in hereditary angioedema and human sepsis. Blood 77(12), 2660-2667 (1991).

24 Suffritti C, Zanichelli A, Maggioni L, Bonanni E, Cugno M, Cicardi M. High-molecular-weight kininogen cleavage correlates with disease states in the bradykinin-mediated angioedema due to hereditary C1-inhibitor deficiency. Clin. Exp. Allergy 44(12), 1503-1514 (2014).

25 Cugno M, Cicardi M, Coppola R, Agostoni A. Activation of factor XII and cleavage of high molecular weight kininogen during acute attacks in hereditary and acquired C1-inhibitor deficiencies. Immunopharmacology 33(1-3), 361-364 (1996).

26 An B, Zhang M, Qu J. Toward sensitive and accurate analysis of antibody biotherapeutics by liquid chromatography coupled with mass spectrometry. Drug Metab. Dispos. 42(11), 1858-1866 (2014).

27 Becker JO, Hoofnagle AN. Replacing immunoassays with tryptic digestion-peptide immunoaffinity enrichment and LC-MS/MS. Bioanalysis 4(3), 281-290 (2012).

28 Heudi O, Barteau S, Zimmer D et al. Towards absolute quantification of therapeutic monoclonal antibody in serum by LC-MS/MS using isotope-labeled antibody standard and protein cleavage isotope dilution mass spectrometry. Anal. Chem. 80(11), 4200-4207 (2008).

29 Neubert H, Fan YY, Fernandez Ocana M. Quantification of protein biomarkers in tissues: new capabilities with pellet digestion peptide immunoaffinity LC-MS/MS. Bioanalysis 8(15), 1551-1555 (2016).

30 Neubert H, Gale J, Muirhead D. Online high-flow peptide immunoaffinity enrichment and nanoflow LC-MS/MS: assay development for total salivary pepsin/pepsinogen. Clin. Chem. 56(9), 1413-1423 (2010).

31 Palandra J, Finelli A, Zhu M, Masferrer J, Neubert H. Highly specific and sensitive measurements of human and monkey interleukin 21 using sequential protein and tryptic peptide immunoaffinity LC-MS/MS. Anal. Chem. 85(11), 5522-5529 (2013).

32 Qu M, An B, Shen S et al. Qualitative and quantitative characterization of protein biotherapeutics with liquid chromatography mass spectrometry. Mass Spectrom. Rev. 36(6), 734-754 (2016).

33 Sano S, Tagami S, Hashimoto Y et al. Absolute quantitation of low abundance plasma APL1beta peptides at sub-fmol/ml Level by SRM/MRM without immunoaffinity enrichment. J. Proteome Res. 13(2), 1012-1020 (2014).

34 Ackermann BL, Berna MJ. Coupling immunoaffinity techniques with MS for quantitative analysis of lowabundance protein biomarkers. Expert Rev. Proteomics 4(2), 175-186 (2007).

35 Berna MJ, Zhen Y, Watson DE, Hale JE, Ackermann BL. Strategic use of immunoprecipitation and LC/MS/MS for trace-level protein quantification: myosin light chain 1, a biomarker of cardiac necrosis. Anal. Chem. 79(11), 4199-4205 (2007).

36 Patel BB, Barrero CA, Braverman A et al. Assessment of two immunodepletion methods: off-target effects and variations in immunodepletion efficiency may confound plasma proteomics. J. Proteome Res. 11(12), 5947-5958 (2012).

37 Shen Y, Zhang G, Yang J et al. Online 2D-LC-MS/MS assay to quantify therapeutic protein in human serum in the presence of pre-existing antidrug antibodies. Anal. Chem. 87(16), 8555-8563 (2015).

38 US FDA. Guidance for Industry: Bioanalytical Method Validation (2001).

www.Fda.Gov

39 Jenkins R, Duggan JX, Aubry AF et al. Recommendations for validation of LC-MS/MS bioanalytical methods for protein biotherapeutics. AAPS J. 17(1), 1-16 (2015).

40 Zhang JC, Claffey K, Sakthivel R et al. Two-chain high molecular weight kininogen induces endothelial cell apoptosis and inhibits angiogenesis: partial activity within domain 5. FASEB J. 14(15), 2589-2600 (2000).

41 Fung EN, Bryan P, Kozhich A. Techniques for quantitative LC-MS/MS analysis of protein therapeutics: advances in enzyme digestion and immunocapture. Bioanalysis 8(8), $847-856$ (2016).

42 Furlong MT, Titsch C, Xu W, Jiang H, Jemal M, Zeng J. An exploratory universal LC-MS/MS assay for bioanalysis of hinge region-stabilized human IgG4 $\mathrm{mAbs}$ in clinical studies. Bioanalysis 6(13), 1747-1758 (2014).

43 Gong C, Zheng N, Zeng J, Aubry AF, Arnold ME. Postpellet-digestion precipitation and solid phase extraction: a practical and efficient workflow to extract surrogate peptides for ultra-high performance liquid chromatography--tandem mass spectrometry bioanalysis of a therapeutic antibody in the low $\mathrm{ng} / \mathrm{ml}$ range. J. Chromatogr. A 1424, 27-36 (2015).

44 Jiang H, Zeng J, Titsch C et al. Fully validated LC-MS/MS assay for the simultaneous quantitation of coadministered therapeutic antibodies in cynomolgus monkey serum. Anal. Chem. 85(20), 9859-9867 (2013).

45 Yuan L, Arnold ME, Aubry AF, Ji QC. Simple and efficient digestion of a monoclonal antibody in serum using pellet 
digestion: comparison with traditional digestion methods in LC-MS/MS bioanalysis. Bioanalysis 4(24), 2887-2896 (2012).

Sandra K, Mortier K, Jorge L et al. LC-MS/MS

quantification of next-generation biotherapeutics: a case study for an IgE binding Nanobody in cynomolgus monkey plasma. Bioanalysis 6(9), 1201-1213 (2014).

47 Zhang G, Zhang Y, Fast DM, Lin Z, Steenwyk R.

Ultra sensitive quantitation of endogenous oxytocin in rat and human plasma using a two-dimensional liquid chromatography-tandem mass spectrometry assay. Anal. Biochem. 416(1), 45-52 (2011).

Lee JW, Devanarayan V, Barrett YC et al. Fit-for-purpose method development and validation for successful biomarker measurement. Pharm. Res. 23(2), 312-328 (2006).

49 Pellacani A, Brunner HR, Nussberger J. Plasma kinins increase after angiotensin-converting enzyme inhibition in human subjects. Clin. Sci. (Lond.) 87(5), 567-574 (1994). 